7 Bittner, T., and Muir, H., Analyt. Biochem. 4, 330-334 (1962).

8 Furano, A. V., Analyt. Biochem., 43, 639-640 (1972).

9 Socldner, J. S., and Slone, D., Diabetes, 14, 771 (1965).

10 Carlsson, L., and Karlsson, B., Experientic, 28, 990-991 (1972)

11 Schill, W. R., and Schumacher, G. F. B., Analyt. Biochem., 46, 502-533 (1972)

12 Schumacher, G. F. B., and Schill, W. R., Analyt. Biochem., 48, 9-26 (1972).

13 Folkman, J., Cancer Res., 34, 2109-2113 (1974).

\section{Enhancement in the sweetness of sucrose}

THERE is considerable interest in the relationship between chemical structure, both configurational and conformational and the sweet response ${ }^{1}$ particularly in the case of sucrose (1) since, of all the sweetening agents it is the most widely used. Hitherto, no derivative of sucrose nor any other carbohydrate has shown sweetness substantially greater than that of sucrose, indeed to the contrary sucrose octa-acetate is very bitter, sucrose monoesters are much less sweet and galacto-sucrose (2), a C4 epimer of sucrose, is greatly diminished in sweetness ${ }^{2}$. Nevertheless, one of the objectives in our studies on the chemistry of sucrose has been to modify its structure, by chemical means in order to enhance its natural sweetness and in the process prevent metabolism by inhibiting breakdown by invertase. We have now been greatly encouraged by the surprising discovery that a galacto-sucrose derivative, namely $1^{\prime}, 4,6,6^{\prime}$-tetrachlorogalacto-sucrose (3) is intensely sweet, comparable with saccharin but without an unpleasant after-taste.
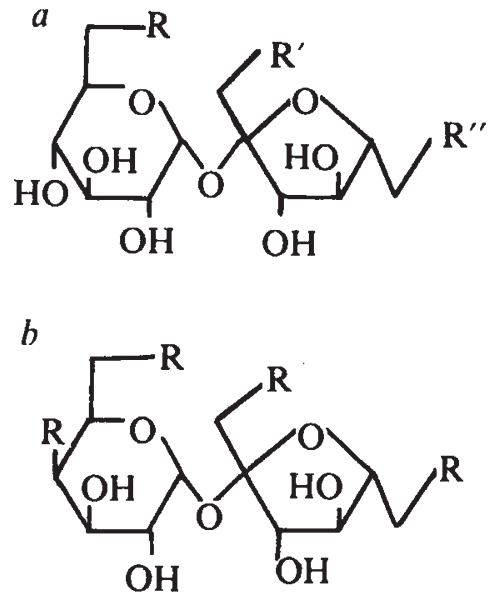

Fig. $1 a$, Sucrose $\left(1 ; \mathbf{R}=\mathbf{R}^{\prime}=\mathbf{R}^{\prime \prime}=\mathrm{OH}\right)$ and its $6,6^{\prime}$-dichloro $\left(4 ; \mathbf{R}=\mathbf{R}^{\prime \prime}=\mathrm{Cl}, \mathbf{R}^{\prime}=\mathrm{OH}\right)$ and $\mathbf{1}^{\prime}, 6^{\prime}$-dichloro $\left(5 ; \mathbf{R}^{\prime}=\mathbf{R}^{\prime \prime}\right.$

$=\mathrm{Cl}, \mathbf{R}=\mathrm{OH})$ derivatives; $b$, galacto-sucrose $(2 ; \mathbf{R}=\mathrm{OH})$ and its tetrachloro derivative $(3 ; \mathrm{R}=\mathrm{Cl})$.

Lindley, Birch and $\mathrm{Khan}^{2}$ suggested from studies on methyl ethers of sucrose that the equatorial 4-hydroxyl group of sucrose (1) interacts with the taste buds of the tongue by intermolecular hydrogen bonding and that loss of sweetness in galacto-sucrose (2) is due to the axial 4hydroxyl group being masked by an intramolecular hydrogen bond to the ring oxygen. Whilst our tetrachloro derivative (3) is not in disagreement with the latter observation, the 4-chloro substituent could only act as a hydrogen bond acceptor on the taste bud. Likewise they suggested the importance of the 1'-hydroxyl group of sucrose which is supported by our own observations in that 6,6 -dichlorosucrose $^{3}$ (4) is less sweet than sucrose, implying that in (3) the 1'4-dichloro substituents are enhancing its sweetness. On the other hand $1^{\prime}, 6,6^{\prime}$-trichloro ${ }^{4}$ and 4,6,6'-trichloro ${ }^{5}$ derivatives are more than 10 times sweeter than sucrose but not as intensely sweet as the aforementioned tetrachloro derivative (3). It is highly significant that $1^{\prime} 6^{\prime}$-dichlorosucrose (5) is intensely sweet, like the tetrachloro derivative (3), which pinpoints the importance of the chloro substituent at the 1 '-position on the molecule of sucrose.

If the Shallenberger theory of sugar sweetness ${ }^{8}$ is correct, where two electronegative atoms A and B separated by 2.5 $4.0 \AA$ initiate the sweet taste by intermolecular hydrogen bonding between $\mathrm{A}-\mathrm{H}$ and $\mathrm{B}$ and similar groups on the receptor site, then it would seem that the $1^{\prime}$-chloro substituent is the proton acceptor $B$ and the 2-hydroxyl on the glucosyl moiety is $\mathrm{A}-\mathrm{H}$, the proton donor. The intense sweetness of the chloro compounds 3 and 5 could also be due in part to their greater lipophilic character than sucrose. The subtle interplay of intramolecular bonding in the sucrose moleculc has an important role and the introduction of chloro substituents seems to have reinforced the effect. The sucrose derivatives in which a 6-hydroxyl of the fructofuranosyl unit of sucrose has been replaced by a chloro substituent are resistant to the action of invertase, a $\beta$-D-fructofuranosidase (J. Chapman, unpublished results). Hence in the development of alternative sweeteners from sucrose, as for example for application in dietetic food, combining high sweetness with low calorie content, the chloro derivatives are worthy of further evaluation.

The material in this publication is included in British Patent Applications No. 616/76 and 19570/76. We thank the International Sugar Research Foundation Inc. and Tate and Lyle Ltd for support.

L. Hough

S. P. Phadnis

Department of Chemistry,

Queen Elizabeth College,

(University of London),

London W8 $7 A H, U K$

Received June 30: accepted September 21, 1976.

I Birch, G. G., Green, L. F., and Coulson, C. B., Sweetness and Sweeteners

(Applied Science Publishers, London, 1971).
Lindley, M. G., Birch, G. G., and Khan, R.,J. Sci. Fd Agric., 27, 140-144 (1976). 3 Hough, L., and Mufti, K. S., Carbohvd. Res.. 25, 497-503 (1972).

4 Khan, R., Carbohyd. Res.. 25, 504-5i0 (1972).

5 Hough, L., Phadnis, S. P., and Tarelli, E., Carbohyd. Res., 44, 37-44 (1975).

6 Shallenberger, R. S., and Acree, 'T. E., Nature, 216, 480-482 (1967).

\section{Erratum}

In the article "Conformation of met"-enkephalin determined by high field PMR spectroscopy" by B. P. Roques et al. (Nature, 262,778; 1976) the legends to Figs 2 and 3 are transposed. The Figs are in the correct positions. The alignment of the stereo picture is incorrect and should be as below.
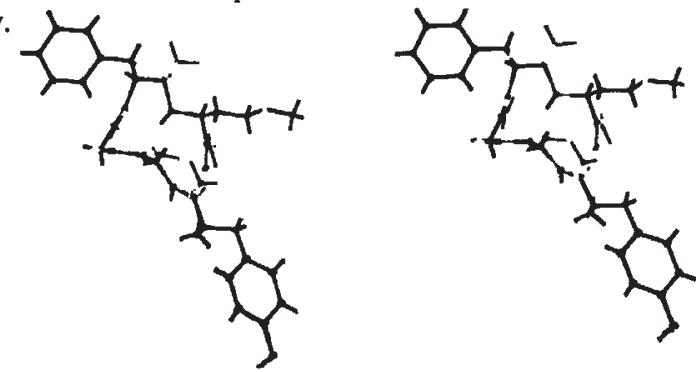

\section{Nature Index and Binders}

The Index for 1975 is now available, price $£ 2.25$. Copies of the 1974 index are still on

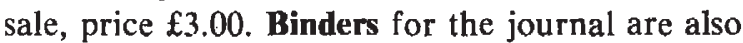
available at $£ 8.00$ for four (a year of Nature fits into four binders).

Postage is included in the above prices. Orders should be sent, accompanied by remittance to Macmillan Journals Ltd, Brunel Road, Basingstoke, Hampshire, England. 